\title{
Inventory Management and Logistics Cost Reduction: A Case of a Malaysia Herbal Medicine Company
}

\author{
Fadilah Siali, Liu Yao, Cheng Jack Kie \\ Faculty of Technology, University Malaysia Pahang, Kuantan, Malaysia \\ Email: fadilahs@ump.edu.my, liuyao@ump.edu.my, jackkie@ump.edu.my \\ Received April 17, 2013; revised May 17, 2013; accepted May 24, 2013
}

Copyright (C) 2013 Fadilah Siali et al. This is an open access article distributed under the Creative Commons Attribution License, which permits unrestricted use, distribution, and reproduction in any medium, provided the original work is properly cited.

\begin{abstract}
Nowadays many studies have stressed the diagnosing inventory systems. This article examined problems encountered on logistics in a Malaysia herbal medicine company. The diagnosis was conducted using the fish bone diagram for the whole supply chain process from the production, hub warehouse, freight forwarders, zone warehouse to customers. The derived results highlight the inventory level management as the root reason, which leads to a set of initial recommendations, including: 1) install the computer-based software system to control inventory level which is to be integrated with the supply chain; and 2) meanwhile implement aggressive marketing approaches to minimize the rate of the returned products.
\end{abstract}

Keywords: Inventory Management; Case Study; Herbal Medicine

\section{Introduction}

As a MBA candidate, have you ever encountered such a question "do you have any idea of how to manage returned products wisely”? Yes, currently the hub herbal medicine warehouse of a herbal marketing company is facing high rate of returned products. Along with it, they have to classify the returned products for repackaging, recycling and remanufacturing for the reverse logistics process. And all these incur higher cost, lower efficiency and customer dissatisfaction.

The herbal marketing company under this study is aimed to form marketable products through Network Marketing (NWM) to whole Malaysia. NWM is a strategy for introducing products to customers. It focuses distributors as key sellers to touch the customers personally and simultaneously the distributor can hire or employ the other distributors in order to ensure the survival of business [1].

The production of the company is provided for two zones: $80 \%$ for Zone A and $20 \%$ for Zone B. There are hundreds of branches under the company. Here take Branch A for Zone A and Branch B for Zone B as examples. Branch $A$ is near to production while Branch $B$ is far away from production. Branch A is the Top 10 branch out of 200 branches with sales around RM100,000 per month; Branch B is not listed as top branch and the sale is around RM200,000 yearly. Branch A has rare and low rate of returned products and Branch B's returned product rate is quite high due to its distance from the headquarters and the production plant.

Actually, from 2009 to 2010, the Branch B faced tough times as the rate of returned products increased from $11 \%$ to $23 \%$, costing around RM69,000. And such significant amount even did not include the cost of transportation for the items' return delivery to the hub warehouse and other hidden costs.

The two key reasons for the returned products are damage and expiry. The majority of the returned products were due to the date of expiry, which brought about RM62,842 losses almost $90 \%$ of the total cost, with 4896 items returned by Branch B. After resorting by groups of products, it is noticed that Herbal Medicine was the biggest contributor of returned products, contributing RM49,075, although only 1744 bottles had passed the expiry dates. In contrast, the beverage and food contributed just over RM12,000 for 3128 items due to expiry dates and only RM534.50 was caused by damage for 59 products. For the cosmetic division, only RM1128 from 24 items were due to expiry dates, and RM5382 from 299 items by reason of damage. In spite of that, consumer products had added in small portion, with RM18 for 2 products that were damaged.

In short, herbal medicines are the main products for the company and the company is confronted with a big 
issue regarding the products expiring in mass amount. Some questions are now emerging-What factors had incurred this issue and how should the relevant parties work to improve this severe situation?

\section{Literature Review}

Broadly speaking, the basic concept of supply chain is the integration of the supplier, production, distributor, retailer, and customer to achieve the ultimate objective. In other words, the supply chain is, as noted by [2] the connected series of activities concerned with the planning and controlling of raw material, components, and finished products from suppliers to the final customers. According to [3], the supply chain is also the process for building improved and stronger upstream and downstream business linkages, consisting of a few elements or members to make the supply chain process run smoothly to ensure the customers can get the products on time and in a particular place.

Being a part of supply chain, inventory is a list of stock and material available. Ballard (1996) classified three types inventory, including: 1) Raw material and components which are defined as the goods, materials and stock that are purchased or bought by an organization; 2) Work in Progress or process (WIP) which is items partly completed or known as semi-finished product with value added; and 3) Finished goods that are completed product and readily to sell in market. And this case study mainly focuses on the third type of inventory which is finished goods [4].

Inventory management and control is very important to an organization since an organization will face a significant loss if there is any failure of inventory management [5]. Mike Benwell (1996) stated that inventory management is started from the suppliers and the errors in supplies will either delay goods receiving, resulting in high volumes of goods waiting attention at the receiving docks; or worse, will get through to the stores unrecorded and affect stock accuracy [6]. Quoted in [7], inventories or stock are a significant portion of the current assets or equity of property to an organization. Errors in an inventory management will create or bring trouble to an organization such as decreasing in productivity, the manufacturing of unwanted items, a reduction in the levels of customer commitment, the accumulation of costly physical inventories and frustration and there will show that a significant unwanted cost to a business [5].

An efficient inventory management can aid an organization to handle their inventory smoothly; with a smooth management, an organization will reduce the inventory lead time, and hence will improve the competitive advantage as gain the trustworthy from the customer [8]. The effectiveness of inventory management will literally in- fluence company financial performance and built a position in competitive advantage ultimately. This is because the approach taken to Inventory Management clearly affects the working capital, production and customer service as well [5].

Generally, herbal medicine products have two years' product life span, and should be sold three months before expiry. Thus, an efficient supply chain process should be emphasized. In Branch B case, the supply chain process is as shown in Figure 1.

\subsection{Production}

Herbal medicine production goes by batches, with 1000 bottles per batch. Each day, the firm can manufacture from eight to 10 batches, amounting to 8000 to 10,000 bottles to meet demand from whole Malaysia. Since the firm sells 30 types of herbal medicines, the production will, each day, concentrate on producing different types of herbal medicines. This indicates that the firm will produce the particular product once a month. However, for certain cases, such as killer products which have high demand, they will produce the items two or three times per month. Another factor that the firm will consider when producing the products is the demand from the hub warehouse which comes from branches and the raw material supplied by the supplier. The expiry date will be set 24 months from the production date.

In this scenario, the firm will store the herbal medicine in their storage for a maximum of two weeks if there is excess production. The over-producing takes place when the demand is less than batches. For example, the demand from the branches throughout Malaysia is 2500 bottles per month, and the firm can produce 3000 bottles due to the machine's capacity. Therefore, the balance of 500 bottles will be stored in the storage for the next demand. The production situation will reflect on the Herbal Medicine life span when the herbal medicines will be deducted two weeks before reaching the Hub warehouse. Eventually, the products shipped by the hub warehouse to the zone B warehouse would have different expiry dates and products life spans.

\subsection{Hub Warehouse}

The hub warehouse is located $50 \mathrm{~km}$ away from the pro-

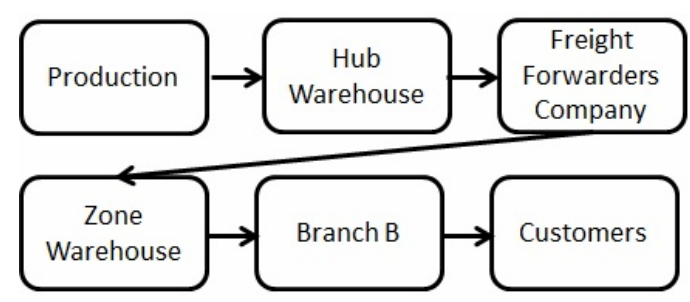

Figure 1. The supply chain process of herbal medicines. 
duction plant. In the supply chain process, the hub warehouse is playing four main roles (seen in Figure 2): managing order process from zone $\mathrm{B}$, making orders to the production department if the Hub warehouse does not have stock, especially for "killer" products; managing the collection process; and handling the loading process.

In normal circumstances, the hub warehouse would receive the order twice a month from the Zone $B$ Warehouse. The order made by the Zone B was not Herbal Medicine solely, but around 50 to 60 types of products. This is because the company seeks to utilize the 20 -foot containers where the weight can carry up to 22 tons in volume provided by the Freight Forwarder Company (which will be explained in detail later in this chapter). Once the hub warehouse receives the approval officially from the logistics and financial unit, the hub warehouse starts the collection process for 50 types of products, which include herbal medicines. In fact, herbal medicines also have their "killer product", whereby they are in high demand, especially in Peninsular Malaysia. In that case, the hub warehouse should make the order to the production within two weeks. The process of collection before shipping would take another two weeks. The final activity done by the hub warehouse is the loading process. The container would arrive at the Hub Warehouse five days before shipping. Thus, it will reach the Hub warehouse on day nine in between the two weeks' time for the collection process. The loading process of the products into the container is done by the staff of the hub warehouse based on the ordering layout given by the logistics unit. Generally, for those herbal medicine products with low demand, the Hub warehouse could store the herbal medicine products for a minimum of three to five months. In that case, the hub warehouse applies the FIFO concept to ensure all the products can be sold three months before expiring. The store people will take herbal medicine products which are "older" than others out to load into the container. This goes without realizing that the FIFO approach will influence the herbal medicines' life spans and the fact that the hub warehouse and the zone B branches do not have any agreement regarding the point in the products' lifespan when it can be shipped to the zone. Eventually, after two weeks are deducted by the production unit, plus three months being kept in the hub warehouse together, with two weeks of the preparation process before shipping the containers, the herbal medicine products' life spans will become shorter, with only 20 months to spare before they are declared to be expired. What's worse? They lack a support system, especially

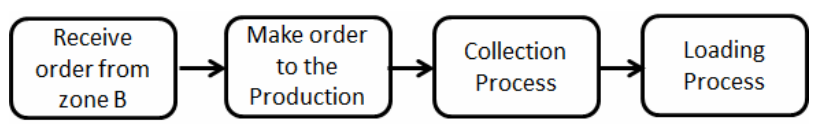

Figure 2. Hub warehouse activities. from the Hub Warehouse and sub warehouse. In other words, the firm's supply chain process works manually by using a stock card which needs to be filled in by the store staff when the products are delivered in and out. Eventually, they begin to fail to identify the average of the inventory level in the warehouse as well as that in the branch.

\subsection{Freight Forwarders Company}

Since 2008, Freight Forwarders Company has been used to develop the zone B market. The service that has been given by Freight Forwarders Company is a "door-to-door service". Door-to-door service is a full package, including the provision of a container, road freight transportation, sea transportation, custom agent, and shipping company.

The process starts when the company books the container from the Freight Forwarders Company. When both of them have agreed the contract, it is considered that the company has already placed the booking. Then, Freight Forwarders Company would send the container five days before shipping and send the container to the designation port one day before the ship departs. The headquarters company will fax the invoice and packing list to the Freight Forwarder Company. Then, the Freight Forwarder Company will submit the invoice and packing list to the Custom for approval. Normally, the approval only takes half a day as the Malaysian Custom uses a particular system for tracking the container before it is loaded into the ship. Once the container enters the port, it is already approved by the custom. To ship the product to the zone B Port, Freight Forwarder Company will use the "custom 3" form stated by the procedure. Normally, the ship takes only a maximum of 10 days to reach the zone B Port. While shipping on board, the Bill of Loading will be faxed to the Freight Forwarders Company who will then courier the container to the zone B warehouse, where it usually takes three days.

There are no critical problems for the Freight Forwarder Company to ensure the container reaches the zone $\mathrm{B}$ Port within 10 days as the shipping schedule runs twice a week. The clearance process from the ship to the port does not take a long time since the zone B Port uses advanced, systematic technology. However, there is a difficulty in berthing the ship at the zone B Port when it depends on the sea' tide. Naturally, the South China Sea has rather unpredictable, and often high, waves. In that case, the ship cannot be berthed. Sometimes, it takes a week to bring the ship into berth, even though the ship has already reached the zone B Port. Therefore, at this juncture, the product's life span will also tend to be affected by natural environments. 


\subsection{Zone B Warehouse (Wholesaler)}

Generally, the zone B Warehouse will make the order twice a month through email and the orders that have been made are based on the demand for the last month, stock balance in the warehouse, and sales in branches. Frequently, herbal medicines constitute $10 \%$ of the 50 different types of products. The distribution process will take around one to three weeks for the products to reach the 14 branches. As no agreement has existed in Hub Warehouse concerning the particular age of product that should be sent to zone B, surprisingly the worst case occurs when arrived in branch $\mathrm{B}$ the herbal medicines are only left with 12 months before expiring. For herbal medicine products, the branch $B$ should send back to the zone's warehouse three months before the products expire for recycling and remanufacturing.

A few more problems have had to be faced by the zone B's warehouse. Firstly, the order process is very slow due to the communication breakdown for the whole supply chain process. The supply chain process is not supported by a system which integrates every layer of the supply chain members. Secondly, the hub warehouse has failed to fulfill the order made by the zone B's warehouse resulting from the raw material shortage and production problem. Thirdly, this zone's warehouse always receives extra quantity of low demand products and eventually has induced surplus products. Another issue arises when Zone $\mathrm{B}$ has to order in mass amount to minimize the water transportation cost without conducting real forecasting for future demand based on the sales trend from the 14 branches operating in that zone.

\subsection{Branch B (Outlet Retailer)}

Based on the branch B's situation, there are several problems identified. The most serious one for branch B, which has failed to sell $30 \%$ of herbal medicine products in a year, is its inability in forecasting demand. Comparing with other branches, branch B is still at early stage. Another reason is that the products' life span is too short. As known to all, herbal medicines are not reactive medicines such as pharmaceutical medicines which can affect immediately. They necessitate ensuring existing customers stay as loyal customers to be valued ultimately. Thus, it is vital that all staffs are fully knowledge the advantages and synergy of herbal medicine, so that their particular and regular customers will gain an understanding of these products. But branch B suffers high turnover due to the salary level and it is difficult for them to train new staff. Another problem is the company applies standardized system involving the point and the product price to all branches which is seemingly difficult for branches to make their own decision to change marketing style. Thus, branch B can hardly be creative according to its own si- tuation while doing marketing strategy.

To sum up, each link in the chain is finger-pointing each other when any issue is raised. The production unit produces based on its own capacity to meet the demand from Hub Warehouse. Even sometimes it faces raw material shortage, the oversupply to Branch B is not their fault; they just follow orders from the hub warehouse. The hub warehouse stressed its distribution function. They complain that only two weeks to fulfill the order is too short, especially for killer products which have high demand. The failure to meet the demand was due to production capacity and it was beyond their control. Moreover, hub warehouse was accusing zone B of failing to forecast the demand wisely.

Freight Forwarders Company was giving the best service to the company, though the natural condition in zone port was beyond their control, which affected the Herbal Medicine lifespan. However, the zone B claimed the surplus products in their warehouse were due to the Hub Warehouse which always gives extra for low demand product in order to optimize the space. And the zone B has to order in mass amounts to minimize the water transportation cost to meet profit margins set by the headquarters. Branch B was disappointed when received lots of complaints about its failure to sell the Herbal Medicine and eventually the products were expired in its place. They felt that it was not completely their fault since they had done lots of marketing activities to ensure the product can be sold before expiry, even still in its infant stage.

\section{Methodology}

To identify the root of the problem of the high rates of returned products in this herbal medicine group, the Ishikawa Diagram, also known as the Fish Bone Diagram, is chosen for the case analysis as it helps visualize the many potential causes of a problem or effect in a display. It is frequently done by taking the possible causes, and measuring their occurrences in various processes.

To construct a Fishbone, one should start by stating the problem in the form of a question. In this case, the problem that has been discussed relate to the high rates of returned products in the branch $B$ is about why the branch $B$ has high rates of returned products? Framing it as a "why" question will help in brainstorming, as each idea should answer the question. Then this question is placed in a box at the "head" of the fishbone.

The rest of the fishbone then consists of one line drawn across the page, attached to the problem statement, and several lines, or "bones," coming out vertically from the main line. These branches are labeled with different categories which consist of six areas, namely material, machine, method, management, man power, and Mother Nature. To gather data related to the case study, several 
interviews had been conducted with different purposes. The full fish bone diagram is provided in Figure 3.

\section{Diagnosis of Branch B Case}

\subsection{Cause 1: Material Issue}

\section{Reasons: Raw Material Shortage}

The first factor of the high rates of returned herbal medicines in the branch B was the Raw material shortage. As noted by the Production Manager, the company produces 30 types of products, with a particular product being produced once a month. Thus, when they are facing high demand for "killer products", they have to face the raw material shortage, which results in the delay in producing the "killer products". Subsequently, the hub warehouse also fails to fulfill the high demand products and there tends to be free space in the container. In that case, the hub warehouse will over-supply even low-demand products to fully optimize the container space, thus incurring surplus products in the zone warehouse.

\subsection{Cause 2: Machine Issue}

Reasons: 1) Capacity Machine Produced by Batch; 2) Depends on Sea Transportation

The production demonstrates its limitation by only producing on batch capacity. Besides thinking about the economy of scale, the production unit considers that it can only produce once a month one product and produce it by batch. However, the demand for the herbal medicine was not by batch ( 1 batch $=1000$ bottles) and it made the production team store or keep the balance of stock for the following demand/order without concerning that it will affect the product's life span. In normal circumstances, the production unit will store the products in their external storage for two weeks, especially for low-demand products.

Moreover, the company completely relies on sea transportation to supply the products. It uses the Freight Forwarders Company which provides door-to-door service and a 20-foot container. In that case, the zone B warehouse will order en masse for high-demand products to utilize the container which considers the profit margin. The hub warehouse will also fill in the container based on the order given by the zone $\mathrm{B}$ after being approved by the logistics unit to ensure the layout and space in the container is in good condition due to the herbal medicine company's role as a shipper. Faced by time constraints, the hub warehouse always fails to fulfill the order, especially for high-demand products. Consequently, the hub warehouse is forced to supply low demand-herbal medicines just to fill up the containers. But the herbal medicines have limited life span and are even lighter than others. Ultimately, this has resulted in the high rates of returned products when the branch $B$ fails to sell it at least within one year.

\subsection{Cause 3: Method Issue}

Reasons: 1) Communication Breakdown; 2) Product positioning; 3) Inventory Level Management; 4) Marketing Approach

The miscommunication problem is a crucial matter

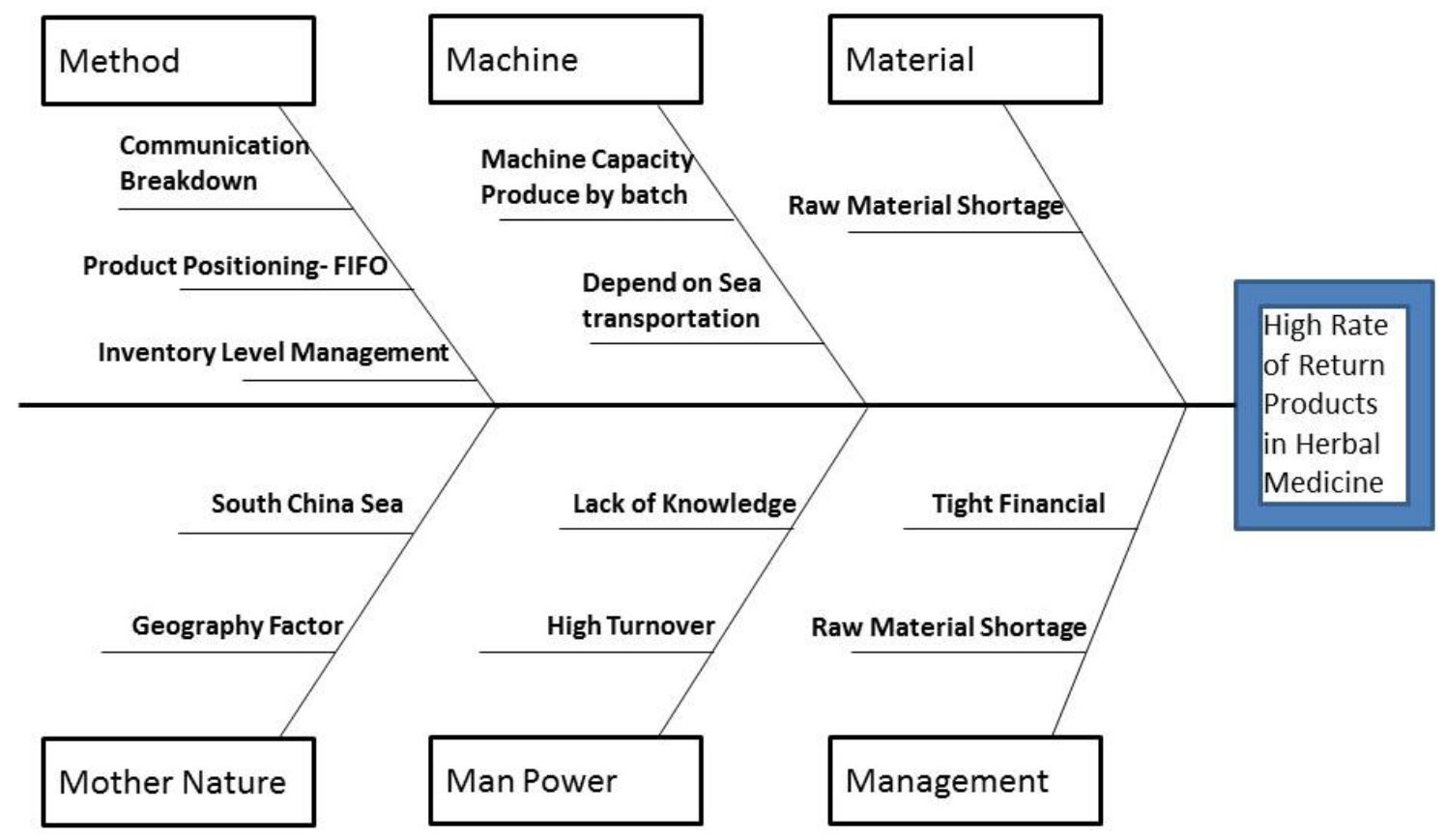

Figure 3. Fishbone diagram for the branch B case. 
because it gives enormous consequences for the whole supply chain process. The supply chain process naturally involves various parties, consisting of the supplier, production, hub warehouse, Freight Forwarders Company, distributor, and retailers. Commonly, the communication breakdown between supply chain members is caused by them working in silos and carrying out their own interests. High rates of returned products are inevitable when the production unit fails to take into account the product life span, the hub warehouse is unable to fulfill the demand and instead over-supplies less-demanded products, the zone B pushes the retailer to sell, which leads to over-supply, and branch B retailer gets all the blame when it fails to sell the products, and eventually $30 \%$ of products expire without being sold. As the supply chain members work in silos and are being selfish, company is likely to suffer losses in the long term.

Generally, all the stores or warehouses which belong to the company apply a FIFO (first-in first-out) approach in order to be able to sell the products three months before their expiry dates. Clearly, the FIFO approach does have its pros and cons. In zone A market which is near to production, the FIFO approach is seen as reliable because the logistics process do not take too long time to process the orders. Normally, the products will arrive having at least 16 months life span. For the zone B condition, the supply chain process instigates the product life span to become shorter. For less-demanded products, the production team will store the products for at least two weeks, and the hub warehouse will store them for around three months, the collection process before shipping will take two weeks, the shipping and berthing process around two weeks, and to distribute from the zone B will take one week. To ensure the returned products can be remanufactured, the outlet retailer is expected to re-deliver three months before the date of expiry. Ultimately, the product life span only stands 16 months for the branch B. Figure 4 demonstrates the supply chain activities which reflect the product life span. Instead of using FIFO, which is not reliable to the zone $\mathrm{B}$, the Hub warehouse actually can use the Last-In First-Out (LIFO) approach to ensure the products with the longest life span are the ones being shipped to the zone B.

The third factor is that the Inventory level management is not supported by systems but works manually. Although this is not the sole cause for the miscommunication, the company has still failed to forecast and calculate the significant buffer stock that should be provided to the zone B warehouse as well as to branch B. It becomes a crisis when branch B fails to cope with the variation in demand. More recently, the Kuching Branch has failed in selling products that were over-supplied.

The final cause in the method issue is the Marketing Approach. The marketing approach of the branch B does

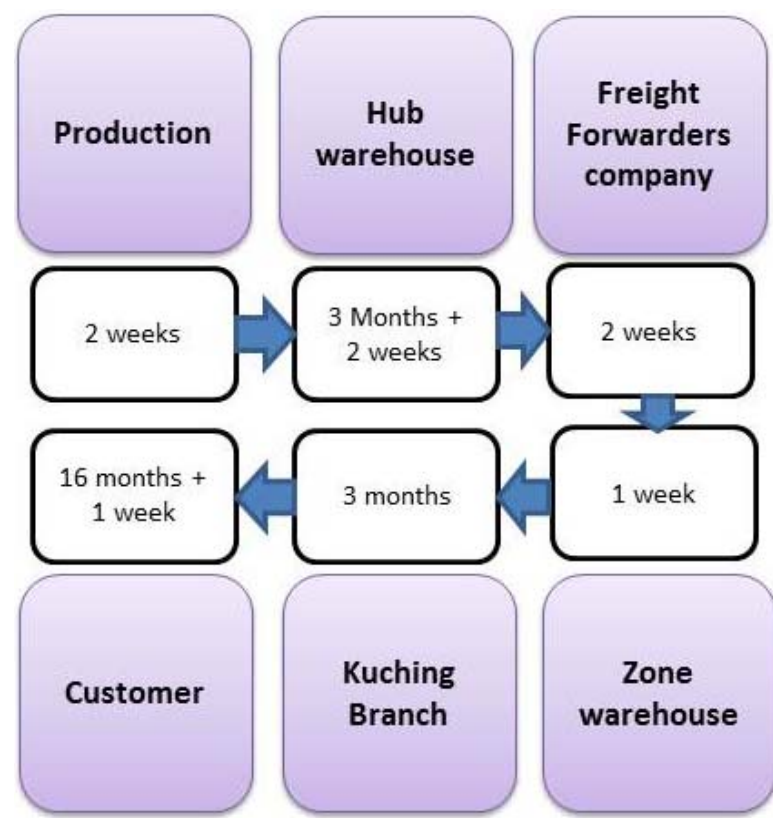

Figure 4. Product life span and supply chain process.

not encourage sales. It completely relies on advertisements by the headquarters for killer products, and the rest of the advertisements are done internally. In fact, it has failed to attract new customers, although they have held some programmes with the purpose of attract existing customers as well as the would-be agents.

\subsection{Cause 4: Management Issue}

Reasons: 1) Tight Financial; 2) Slow Ordering Process

When facing a tight financial situation, the company has to use sea transportation, which is less costly than air transportation. As producing 400 types of products, the company has decided to use 20-foot containers, which are cheaper than air transportation for transporting the products to the zone B. Even if the loose cargo is less expensive than the 20 -foot containers, it is not good for the company to ship 50 types of products twice a month. Nonetheless, it also tends to initiate the high rates of returned products if they cannot be managed properly when they oversupply the products which are of less demand to make full use of the 20 footer containers.

The second crucial issue is the culture which has been embedded in the company. The company's organization structure is exceptionally large as shown in Figure $\mathbf{5}$. Thus, the ordering process is slow because the hub warehouse has to ask for the approval of the financial and logistics units first, before arranging with the Freight Forwarder Company to provide their door-to-door service. Ideally, the approval would take three days, but it normally extends to one or two weeks for the collection process to be completed before the products are shipped. The sales rates of herbal medicines products tend to in- 


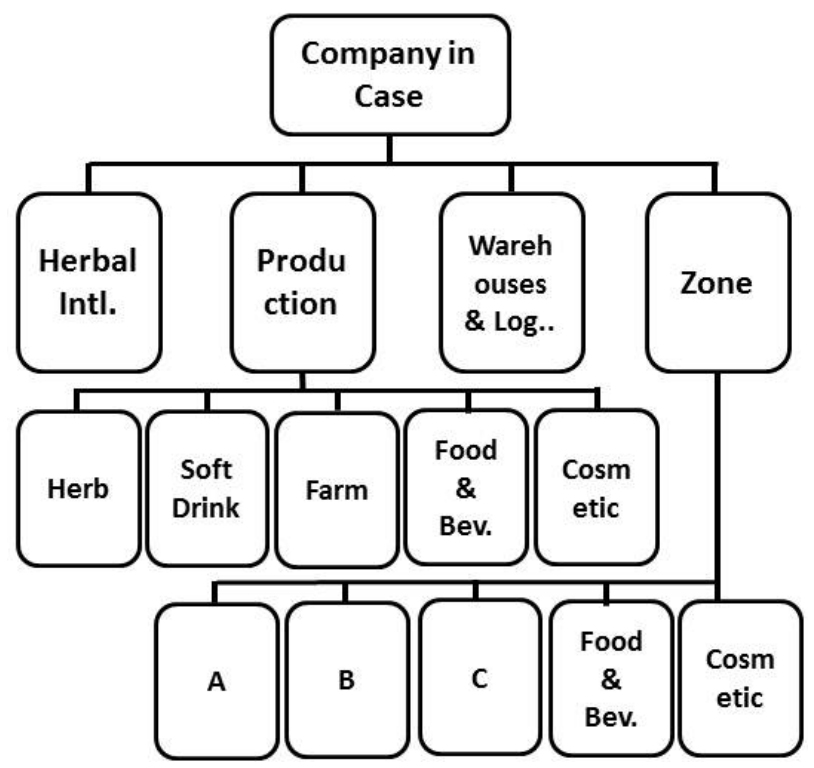

Figure 5. Organization structure.

crease in certain months because they are seasonal products. When it finally arrives in zone $\mathrm{B}$, the season is already over, and, consequently, it creates surplus products which will, eventually, be overdue.

\subsection{Cause 5: Manpower Issues}

Reasons: High Turnover; Lack of Knowledge

As observed by the Logistics Manager, high turnover occurs because the salary level does not meet the actual cost of living, especially in zone $\mathrm{B}$. The rate of turnover can disrupt the marketing process and is costly due to the need to train new staff. Untrained new staff will invariably influence customers' perception. Ultimately, the brand name will be affected, and the number of customers will plummet.

The Headquarters provide a test once per three months. This is clearly not enough, since the test is only general and does not deal particularly with herbal medicine products. As far as the difficulty in selling herbal medicines is concerned, it shows that branch B has failed to propagate the multiple benefits of herbal medicines to their customers. Therefore, the surplus products cannot be reduced and, as a result, are returned to zone B warehouse.

\subsection{Cause 6: Natural Phenomena}

\section{Reasons: South China Sea; Geographic Factors}

The South China Sea has high waves which cannot be predicted. This attributes to the agility of the weather. Ships cannot be berthed during periods of high waves on the South China Sea and, understandably, it is beyond the Freight Forwarder Company's control. Sometimes it takes a week to bring the ship into berth, even if the ship had already reached the zone B Port several days earlier. Au- tomatically, the product life spans will be affected due to the delay stemming from this natural phenomenon.

Geographically, zone A and zone B are separated by the South China Sea. The company has to spend time and money developing new markets in zone B by using sea transportation, which is less costly than air transportation. But the problem occurs when the company does not have a proper managing system, so that the rates of returned products have escalated.

After all the processes have been diagnosed, it is found that the high rates of returned herbal medicine products are mostly caused by method issues, including inventory management, marketing approach, product positioning, and communication breakdown.

\section{Solution Recommendations}

\subsection{Short-Term Plan of Action}

In a short term, the company can improve the daily manual work of the physical inventory count by applying ABC analysis also called "usage-value analysis”. ABC analysis categorises a range of items, from inventory levels to customers and sales territories, into three groups: $\mathrm{A}=$ very important; $\mathrm{B}=$ important; $\mathrm{C}=$ marginal significance. The goal is to categorise items to be prioritized, managed, or controlled in different ways.

In this case, to reduce the returned products, the branch B can use ABC analysis to apply different ways of marketing approach to ensure the product be sold before expiry. It can assign an employee a checking process of physical inventory count daily to identify the groups of A, $\mathrm{B}$, or $\mathrm{C}$ products based on sales and product lifespan. This activity is cost-free, though it needs the commitment of the employees in the outlet retailer. The ABC analysis will be done as in Table 1.

\subsection{Long Term Investment-Install Inventory Control System}

We suggest the company install the computer-based software system to control the inventory level which is to be integrated with the supply chain team. The inventory software is readily available in the market and the top management of $\mathrm{OHI}$ should endeavor to purchase it as soon as possible. With this suggestion, there are two types can be taken for consideration.

\subsubsection{Custom-Made Software System}

As known, the company produces 400 types of products categorized into five groups: cosmetic, herbal medicine, food and beverage, frozen products, and consumer products. Its supply chain process involves different suppliers, contract manufacturers and owned manufacturer and around 200 branches in five zones in Malaysia. As it is so complex, we would suggest the company hire a con- 
Table 1. ABC analysis for Branch B.

\begin{tabular}{|c|c|c|}
\hline Type & Description & Action \\
\hline A & $\begin{array}{l}\text { Very important: } \\
\text { Short product life span and less demand }\end{array}$ & $\begin{array}{l}\text { Aggressive promotion for short term } \\
\text { Example: Buy one, get one free (with achieved profit margin) }\end{array}$ \\
\hline B & $\begin{array}{l}\text { Important: } \\
\text { Long product life span and less demand }\end{array}$ & $\begin{array}{l}\text { Promotion for long period of time } \\
\text { Example: Discount price or volume more for one bottle (with achieved profit margin) }\end{array}$ \\
\hline $\mathrm{C}$ & $\begin{array}{l}\text { Marginal significance: } \\
\text { Long product lifespan and high demand }\end{array}$ & Standard marketing approach and no promotion \\
\hline
\end{tabular}

sultant to create an inventory computer system online and integrate all supply chain team which tailor made to the nature of the company's operation. Although the custom-made system is actually a very expensive investment, it will largely reduce the returned products cost and improve operation for recycle and remanufacturing. It would also be helpful for the hub warehouse to forecast demand and make manufacturing order.

\subsubsection{Generic Software-Inventory Control System}

Alternatively, the company can also purchase the license of generic software which lots of software developer companies sell throughout Malaysia and which is cheaper than custom-made software. Here introduce three options for consideration.

Supply Chain Inventory Management (SCIM) offers a dynamic and effective way of monitoring company's day-to-day inventories and allowing an organization to take immediate action to address any potential inventory problems. With SCIM, the company can gain an in-depth, real-time visibility into key supplier, inventory, and procurement indicators. The company will be able to better manage inventory levels and costs, and better meet fulfillment expectations, thus improving customer service. Other benefits include: Eliminates manual inventory management processes and improve vendor satisfaction with a seamless procure-to-pay process; Slashes inventory costs by tightening control of stock levels while increasing operational efficiencies; and gains control over inventory replenishment and ensures that inventories have enough on-hand to fill anticipated orders, while keeping excess stock to a minimum, etc.

Track $^{\mathrm{TM}}$ Warehouse and Retail Management System and RFID applications - it offers: 1) pallet and case tracking, particularly when the pallets are reused within a closed system; 2) forklift identification, RFID can identify forklift location to allow systems to monitor activity and assign the closest forklift to those pallets needing moved, and serve as a permanent asset ID; 3) access control: Chips embedded in ID cards can control locks and prevent unauthorized entry; chips on products, cases, pallets and equipment can control item movement and sound alarms in case of unauthorized removal; 4) smart shelves: Retailers are experimenting with readers embedded in stocked store shelves to keep track of tagged inventory and notify either the backroom or supplier when stock is low.

Inventory Control \& Valuation System (ICVS) is allinclusive, functionality-rich software. It meets all the requirements for efficient management of inventories and materials procurement functions of small to large scale organizations. ICVS is integrated with demand management and order entry, financial accounting, and shop-floor control for automatic calculation of material requirements, generation of payables and issuances of materials upon authorization to departments and shop-floors respectively. Therefore, whether the company is a manufacturing concern, a distribution company or a service-based organization, ICVS provides tremendous help in the preparation of sound production, distribution, and supply plans by enabling valid and real-time records of inventories. While simultaneously protecting from unforeseen stock shocks, ICVS can also be easily integrated with other packaged software applications.

\subsection{Marketing Approach}

According to the analysis given, it is identified that the branch B has faced variations in demand, as well as surplus products, which, towards the end, has induced the increased number of returned products, particularly where herbal medicines are concerned. Although herbal medicine products have the privilege to reuse and remanufacture it, it incurs high costs, particularly with respect to transportation. Here, we suggest that aggressive marketing activities can be used to achieve zero returned products from branch B and to gain the market share in zone B. Details are shown in Table 2.

\section{Conclusion}

This paper addressed the problem of high rate of returned herbal medicines in a herbal medicine company in Malaysia. It found that by the time herbal medicine products arrived at branch B, the product life span left only 16 months before it expired. The fishbone diagnosis revealed manual practices in the inventory process in each level of supply chain process as well as the inefficiency of communication between them to be the main causes. There is a lack of understanding amongst the supply chain members to cope with the variation in demand existing in the 
Table 2. Suggested marketing approach.

\begin{tabular}{|c|c|c|}
\hline & Marketing approach & Description \\
\hline 1 & $\begin{array}{l}\text { Introduce new uses for the } \\
\text { product (Multifunction) }\end{array}$ & $\begin{array}{l}\text { Outlet retailer employees should have knowledge of selling herbal medicine and the ability to discuss their } \\
\text { multiple functions. Once customers step into the shop and even buy one herbal medicine, they can digest } \\
\text { the synergy information of herbal medicine. In this way, they can attract customers. }\end{array}$ \\
\hline 2 & $\begin{array}{l}\text { Offer price incentives for } \\
\text { increased use (buy two, free one) }\end{array}$ & $\begin{array}{l}\text { When branch B is facing the short product life span, they can take aggressive action by offering price } \\
\text { incentives. The new price offer should obtain the profit margin for particular products. Even though this } \\
\text { approach does not generate too much profit, it is likely to achieve the aim of zero returned products, thus } \\
\text { avoid returned product cost. }\end{array}$ \\
\hline 3 & $\begin{array}{l}\text { Increase efforts to } \\
\text { attract non-users }\end{array}$ & $\begin{array}{l}\text { Branch B should attract customers who buy other products instead of the herbal medicine by starting with } \\
\text { promotion and package offers to convince them that they are not wasting their money in buying the } \\
\text { products. Thus, those non-herbal medicine users can be their potential customers. }\end{array}$ \\
\hline 4 & Sep up promotion & $\begin{array}{l}\text { Branch B should not rely on advertisement by the Headquarters. They should set up their own promotion } \\
\text { concept by attracting new customers. They can do aggressive activities by opening booths in any residential } \\
\text { areas, or by getting the herbalist club to offer free (or inexpensive) medical checkups and traditional } \\
\text { medical services, such as acupuncture, chiropractic, reflexology, etc. to attract more new customers. They } \\
\text { also can set up main annual activity to have road show in all the resident places and take part in community } \\
\text { activity for promotion. }\end{array}$ \\
\hline 5 & $\begin{array}{l}\text { Increase service trial through } \\
\text { offering samples and incentives }\end{array}$ & $\begin{array}{l}\text { For the less demanded products, branch B can demonstrate to new customers who do not know about the } \\
\text { particular products. They can offer service trials by offering samples of each product. They can also } \\
\text { charge special prices for new customers, at the same time, offer them the experience of using a bottle of } \\
\text { herbal medicine for a particular purpose. }\end{array}$ \\
\hline 6 & $\begin{array}{l}\text { Develop new product features by } \\
\text { attempting to adapt, modify, magnify, } \\
\text { minimize, substitute, rearrange, } \\
\text { reverse, or combine existing features. }\end{array}$ & $\begin{array}{l}\text { The main debility of herbal medicine is that the bottle features are not attractive. It also does not display } \\
\text { the products' functions which can influence customers to have a look and buy it. Therefore, the company } \\
\text { should develop new product features by attempting to adapt to customer needs as well as comparing } \\
\text { themselves to their competitors. }\end{array}$ \\
\hline 7 & Develop additional sizes & $\begin{array}{l}\text { To make multi choice and different prices, the production unit can produce two different sizes in order to } \\
\text { attract first trail consumer who is less confident of the products. The different sizes and prices are actually } \\
\text { psychological approaches that can be used to attract new customers. }\end{array}$ \\
\hline
\end{tabular}

market. The case study also indicates that the production team should produce with numerous amounts whereas the branches failed to sell it. The branch marketing activities rely on the main promotion activities of the headquarters. The company shall assist branch to create many types of marketing activities, since branch $B$ is relative new in zone B. A set of recommendations has been proposed accordingly also for other branches facing the same situations and complexities. Future study can pay more attention to other issue, such as the reverse logistics process, high turnover, and the decentralized system used by the company.

\section{REFERENCES}

[1] P. Msweli and A. Sargeant, "Modelling Distribution Retention in Network Marketing Organization," Marketing Intelligence \& Planning, Vol. 19, No. 7, 2001, pp. 507514. doi:10.1108/EUM0000000006215

[2] S. Vickery, R. Calantone and C. Droge, "Supply Chain Flexibility: An Empirical Study,” Journal of Supply Chain Management, Vol. 35, No. 3, 1999, pp. 16-24.

[3] R. B. McAfee, M. Glassman and E. D. Honeycutt Jr.,
"The Effects of Culture and Human Resource Management Policies on Supply Chain Management Strategy," Journal of Business Logistics, Vol. 23, No. 1, 2002, pp. 1-18. doi:10.1002/j.2158-1592.2002.tb00013.x

[4] R. L. Ballard, "Methods of Inventory Monitoring and Measurement,” Logistics Information Management, Vol. 9 No. 3, 1996, pp. 11-18. doi:10.1108/09576059610116653

[5] N. Rajeev, "Inventory Management in Small and Medium Enterprises: A Study of Machine Tool Enterprises in Bangalore,” Management Research News, Vol. 31 No. 9, 2008, pp. 659-669. doi:10.1108/01409170810898554

[6] M. E. Benwell, "Scheduling Stocks and Storage Space in a Volatile Market," Logistics Information Management, Vol. 9, No. 4, 1996, pp. 18-23.

[7] G. Filbeck and T. Krueger, "Industry Related Differences in Working Capital Management," Journal of Business, Vol. 20, No. 2, 2005, pp. 11-18. doi:10.1108/19355181200500007

[8] C. Wallin, M. J. Rungtusananthan and E. Robinovich, "What Is the Right Inventory Approach for a Purchased Item?” International Journal of Operation \& Production Management, Vol. 26, No. 1, 2006, pp. 50-68. $\underline{\text { doi:10.1108/01443570610637012 }}$ 